\title{
AN EXPERIMENTAL INVESTIGATION ON STRENGTH PROPERTIES OF STEEL FIBRES ALONG WITH RECYCLED AGGREGATE IN CEMENT CONCRETE
}

\author{
S. Prakash Chandar, K. Gunasekaran, N. Sai Sandeep \\ and S. Manikandaprabhu ${ }^{4}$ \\ Department of Civil Engineering, SRM University, Kattankulathur \\ E-mail:ramprabu862@gmail.com
}

\begin{abstract}
Concrete is a composite material which is hard and brittle shows some special characteristics by surprising the modern construction industry. In the earlier stage of the $17^{\text {th }}$ century, concrete has become a revolutionary material and got success in the field of construction. In developing the alternatives to the concrete, a new replacement to coarse aggregate has been made and is named as recycled aggregate concrete. Here demolished building material is used as a coarse aggregate. Thus the concrete made from this is also known as reborn concrete. This has high compressive strength and impact strength when compared to normal concrete, But concrete is strong in compression and weak in tension, so as to overcome this problem the use of fibres in concrete will control the problem of weakness in tension. This fibre usage will arrest the crack failure and will promote the growth of concrete strength in all aspects. As the steel fibres are the better fibres, so they can resist the crack failure a lot more than the others. This Experimental study deals with the study on mechanical and structural properties of concrete adding steel fibres in percentage 0.5 to 2 with full replacement of recycled aggregate
\end{abstract}

Keywords: Recycled aggregate, steelfibres, compressive strength, demolished material, reborn concrete

(C) RASĀYAN. All rights reserved

\section{INTRODUCTION}

Concrete is most commonly used construction material in the world of construction industry due to it has the ability to mouldto a shape. When in fresh stage by changing the ingredients in the concrete conventional material, aggregate and water also by adding some special ingredients may lead to change in strength and durability of concrete. Even though concrete is used for many applications, it has some deficiencies as given below:

1. Low tensile strength

2. Low post cracking capacity

3. Brightness and low durability

4. Limited fatigue life

5. Low impact strength

In recent years, the growth of urbanization least to removal aged buildings. This removal creates environmental pollution so, as an alternate demolished building aggregate is selected for the production of concrete by replaced with coarse aggregate.

The concrete made with this ordinary recycled coarse aggregate (RCA) has been investigated such that to compare the concrete made with natural coarse aggregate (NCA) the maximum size of RCA obtained by crushing or other process is less then $31.5 \mathrm{~mm}$ but, now recycled aggregate concrete is not widely used (Tan LI).As we know concrete is brittle material and is weak in tension. So, this may generate the crack easily. This problem has made the introducing of steel fibres into concrete. (These steel fibres have high elasticity and high tensile strength) steel fibres include the strength property, toughness and stress resistance. Steel fibre reinforced concrete has many applications in flooring, pre cast tunnelling, heavyduty pavements and mining. By using both ingredients, fibre reinforced recycled aggregate concrete can 
be produced, such that this can decrease the environmental damage and will increase the strength properties of concrete.

\section{Material used}

\section{EXPERIMENTAL}

In this project, the materials used are 53OPC Cement, River sand, demolished building aggregate, steel fibres. The materials are arranged from the nearest store, where recycled aggregate was collected from the nearest buildings waste.

\section{Cement}

Cement is a powder form .it terms into past when mixed with water, this is due to the content limestone in it. The 53 grade OPC type of cement is corrected from the nearest store.

\section{Sand}

Sand is the other most important construction material that is needed to prepare concrete. Sand is a fine material which is present at the river bed. The sand is collected from the nearby river and sieved through $4.75 \mathrm{~mm}$.

\section{Recycled coarse aggregate [RCA]}

The coarse aggregate replaced with demolished building material,the material was brought to the lab and it was demolished with the hammer of $5 \mathrm{~kg}$ weight. The demolished material was sieved through $20 \mathrm{~mm}$ size.

\section{Steel fibres}

Steel fibres that are using in the concrete are manufactured in a way such that they should not be corroded. The steel fibre here we are used a hooked type of steel fibres. The composition of steel fibres are carbon, silicon, manganese, phosphorus, sulphur and other elements.

\section{RESULTS AND DISCUSSION}

The tests were done on the concrete specimens are moulded as cubes, cylinders, Reinforced beams. The casted specimens were allowed to test at the age of 3,7and 28 days.The mixed grade is M25.

\section{Compressive strength test}

Compressive strength is the internal resisting force of the body towards the load applied on it. This test is carried out on concrete cubes in the compressive testing machine (CTM). The cube is placed in between the two supporting. where the contacting surfaces must be plain and flat. The size of the cube specimen is $150 \mathrm{~mm} \times 150 \mathrm{~mm} \times 150 \mathrm{~mm}$. The obtained test results are as in Table-1.

Table-1: Compressive strength test Values for CC and RCA with addition of steel fibres

\begin{tabular}{c|c|c|c|c}
\hline \multirow{2}{*}{ Mix } & \% of Fiber & 3rd Day & 7th Day & 28th Day \\
\hline Conventional concrete & 0 & 18.2 & 22.62 & 31.7 \\
\hline \multirow{3}{*}{$\begin{array}{c}\text { Recycled aggregate } \\
\text { concrete with addition of } \\
\text { fibers }\end{array}$} & 0 & 18 & 22.5 & 30.95 \\
\cline { 2 - 5 } & 0.5 & 18.6 & 22.72 & 33.3 \\
\cline { 2 - 5 } & 1 & 19.2 & 23.64 & 35.1 \\
\cline { 2 - 5 } & 2 & 18.03 & 21.12 & 32.98 \\
\hline
\end{tabular}



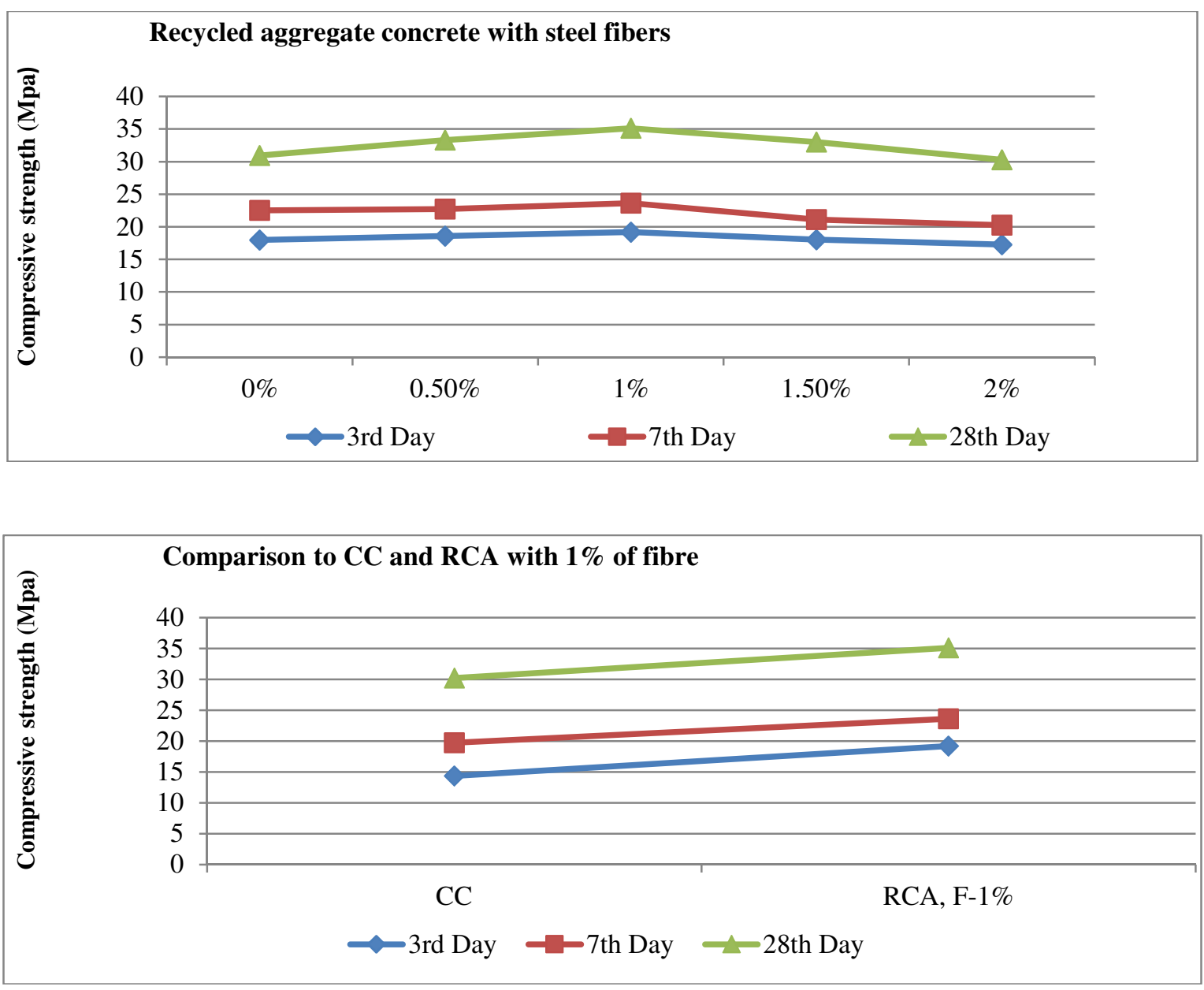

Fig.-1: Graphical representation for RCA with the addition of fibre

\section{Split tensile strength}

It is the test performed on concrete cylinders. It is the resisting force of a body when the load is applied away from the body tensile strength is the important test to be kept in mind to determine concrete strength. We all know concrete is strong in compression and weak in tension so alternatives are to be taken to overcome this problem. The specimen used for testing the cylinder is of size $300 \mathrm{~mm}$ height and $150 \mathrm{~mm}$ diameter. The cylinder must be placed horizontally on the line of contact should be throughout the length. The test results are as in Table-2.

Table-2: Split tensile Strength test results for CC and RCA with addition of fibre

\begin{tabular}{c|c|c|c|c}
\hline \multicolumn{2}{c}{ Split tensile strength (Mpa) } \\
\hline \multirow{2}{*}{ Mix } & \% of Fiber & 3rd Day & 7th Day & 28th Day \\
\hline Conventional concrete & 0 & 2.5 & 2.77 & 3.01 \\
\hline \multirow{3}{*}{$\begin{array}{c}\text { Recycled aggregate } \\
\text { concrete with addition of } \\
\text { fibers }\end{array}$} & 0 & 1.9 & 2.66 & 2.9 \\
\cline { 2 - 5 } & 0.5 & 2.11 & 2.68 & 3.17 \\
\cline { 2 - 5 } & 1.5 & 2.82 & 2.92 & 3.76 \\
\cline { 2 - 5 } & 2 & 2.76 & 3.21 & 3.9 \\
\hline
\end{tabular}



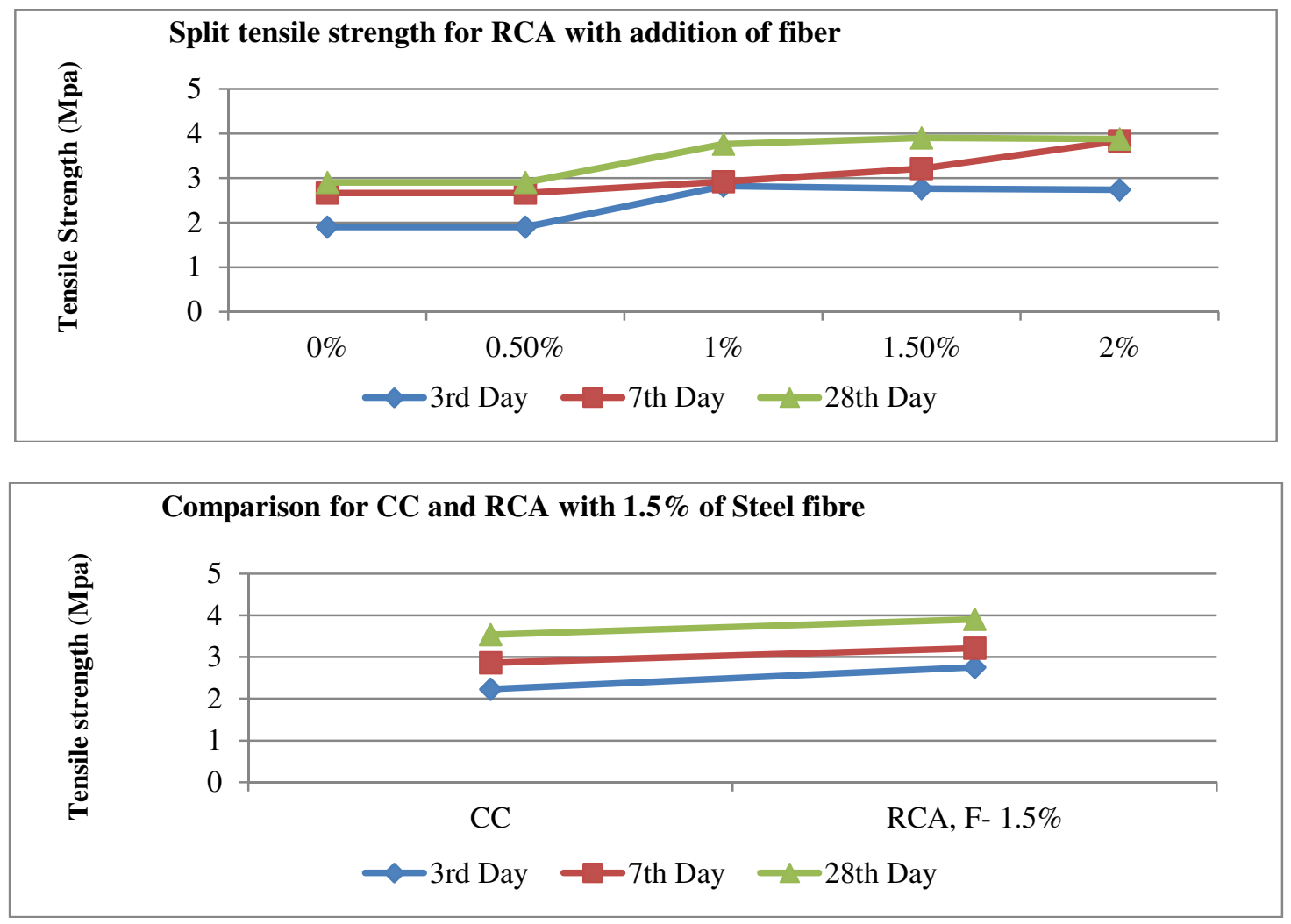

Fig.-2: Line Diagram for CC and RCA with addition of fibre

From the above test results, it was clearly known that at $1.5 \%$ addition of fibres it has obtained increasing tensile strength when compared with the Conventional concrete. In fig 2 it was shown clearly with line diagrams.

\section{Failure Analysis of RC Beam}

Testing of reinforced beam is the most important thing in investigating the behaviour of concrete. Deflection in the beam will determine the failure at maximum load. This can be determined by testing the beam with two-point loading and also by placing deflect meters at the bottom of beam this will determine the change in length when the beam bends under loading.

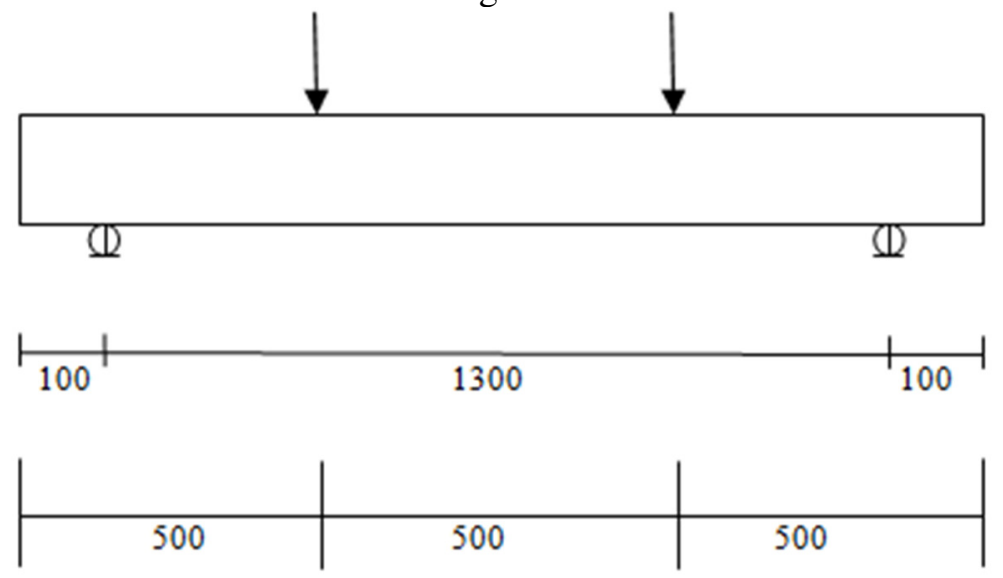

Fig.-3: Loading Schematic Diagram (dimensions in $\mathrm{mm}$ ) 
The beam was prepared in wooden moulds of sizes $1500 \mathrm{~mm}$ length, $150 \mathrm{~mm}$ wide and $230 \mathrm{~mm}$ depth. A total of 6 beams were cast and tested they are conventional concrete, recycled aggregate concrete and recycled aggregate concrete with the addition of steel fibres in percentages from 0.5 to 2 . The reinforcement provided with $10 \mathrm{~mm}$ bars placing along the length and $6 \mathrm{~mm}$ bars used as stirrups with a spacing of $150 \mathrm{~mm}$ centre to centre. The tested beam values with deflection are as in the following table.

Table-3: Load - Deflection values of Reinforced beams with addition of steel fibres

\begin{tabular}{c|c|c|c}
\hline S. No. & Code & Break Load (T) & $\begin{array}{c}\text { Maximum deflection @ centre } \\
(\mathrm{mm})\end{array}$ \\
\hline 1 & CC & 14.8 & 6.21 \\
\hline 2 & RAC, F-0\% & 12.45 & 5.06 \\
\hline 3 & RAC, F-0.5\% & 18.85 & 7.38 \\
\hline 4 & RAC, F-1\% & 25.25 & 6.7 \\
\hline 5 & RAC, F-1.5\% & 31.61 & 6.91 \\
\hline 6 & RAC, F-2\% & 38.05 & 6.12 \\
\hline
\end{tabular}

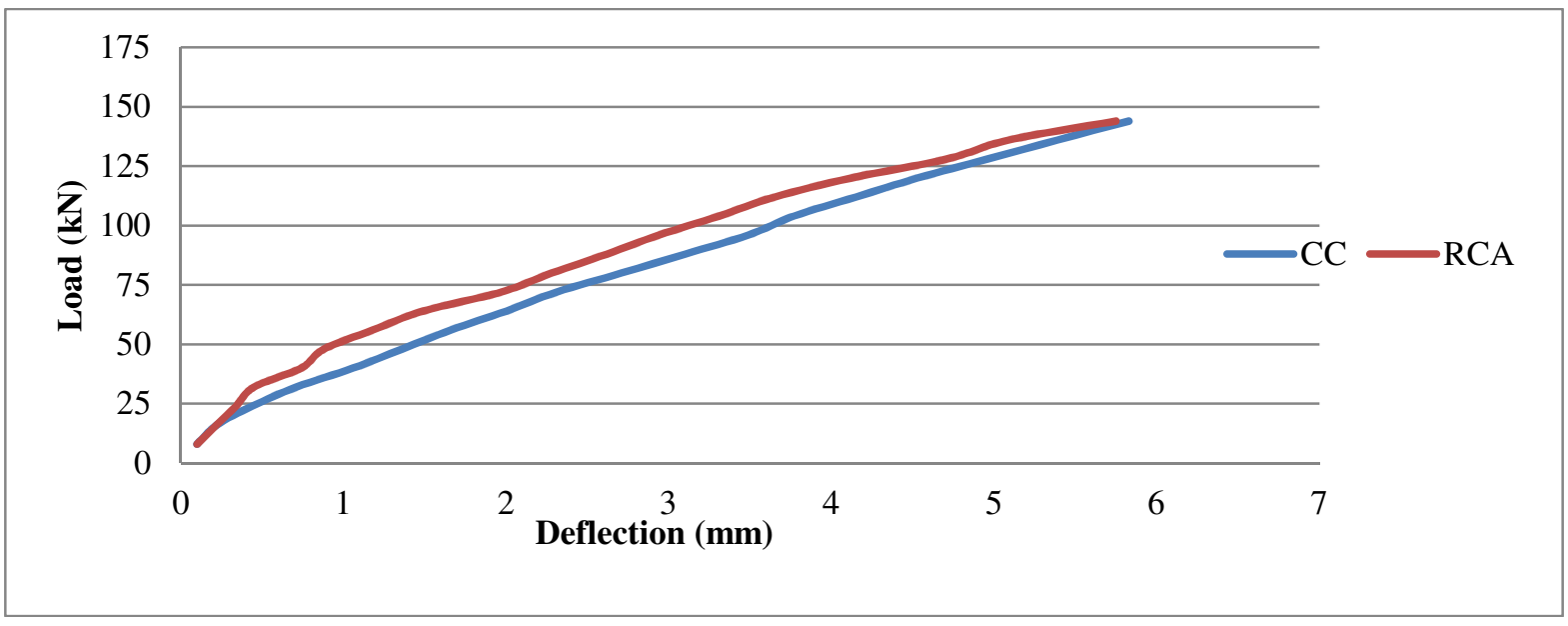

Fig.-4: Load Deflection Curve (CC \& RCA)

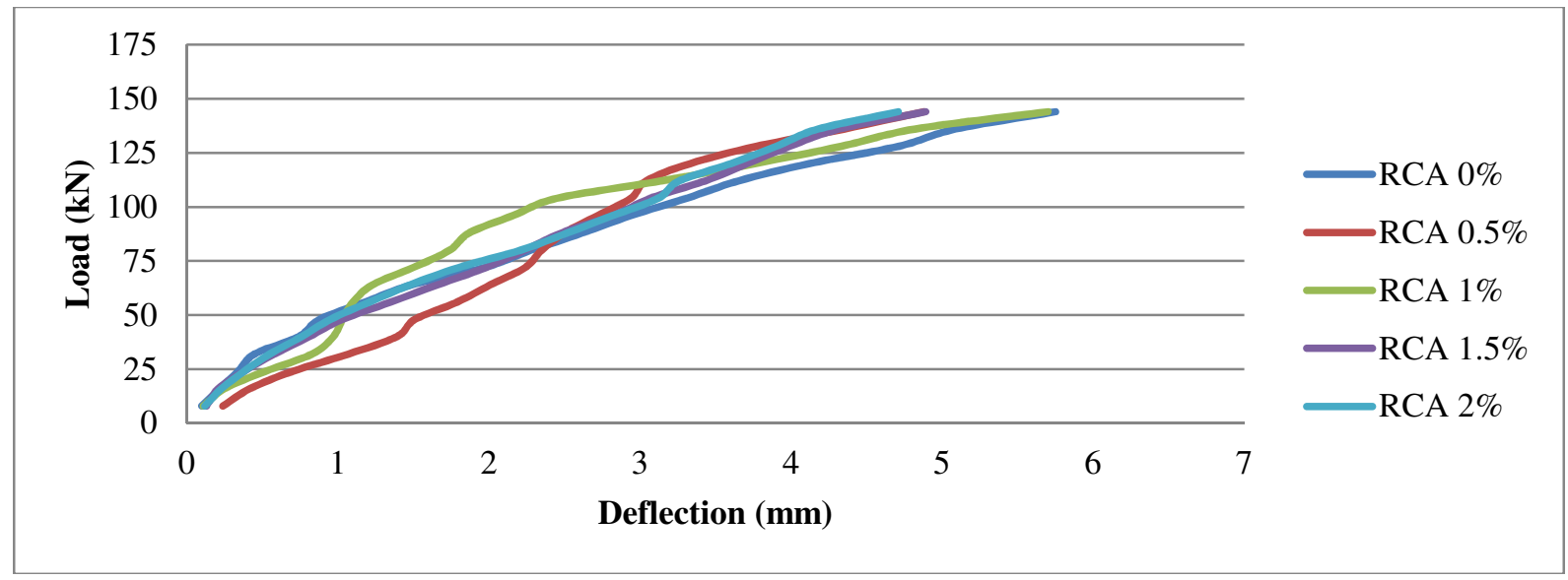

Fig.-5: Load Deflection Curve (RCA 0\%, 0.5\%, 1\%, 1.5\%, 2\%) 


\section{CONCLUSION}

From the results obtained, the following conclusions were drawn:

- In the previous study, the authors and researchers have concluded that whenever the increasing the content of steel fibers will affect the compressive strength of concrete. The increasing in the percentage of steel fibers makes reduction in compressive strength.

- With the incorporation of recycled aggregate in the place of conventional aggregate in the concrete, compressive strength decreased by $2.36 \%$. Whereas addition of steel fibers in the above mixes slightly increased the strength of the concrete by $10 \%$ at $1 \%$ of steel fibers usage.

- The best Compressive strength occurred at $1 \%$ of steel fibers usage, where the compressive strength is $35.1 \mathrm{MPa}$.

- The split tensile strength and flexural strength was largely increased between $1 \%$ and $1.5 \%$ of steel fibres.

\section{REFERENCES}

1. A. Gonzalez Corominas and M. Etxeberria, Construction and Building Materials, 32,41 (2014)

2. A. M. Shende, A. M. Pande and M. GulfamPathan, International Refereed Journal of Engineering and Science, $\mathbf{4 3 , 4 8}$ ( 2012)

3. C. Thomas, J. Setien and J. A. Polanco, Construction and Building Materials, 536,546 (2016)

4. G. Murali, C. M. VivekVardhan, G. Rajan, G.J. Janani, N.ShifuJajan, and R.RamyaSri, International Journal of Engineering Research and Applications, 2,407(2012)

5. J. Trckova and F. Petrprochazka, International Research Journal of Engineering and Technology, Vol 8,105(2011)

6. K. Lahamge, International Journal of Research in Engineering and Technology, 5, 32(2016)

7. G. Surelli ,A. Meda, and A. Plizzari, ACI Structural Journal , 103, 116,(2006)

8. T. Krishna, International Research Journal of Engineering and Technology, 2, 58(2015.)

9. D. Gao, L.Zhang,V M.Nokken, International Journal of Cement Composites and Lightweight Concrete, 1, 8 ( 2017)

10. G.M. Chen, H. Yang, C.J. Lin, J.F. Chen, H. Zhang, Construction and Building Materials, 272, 286 (2016)

11. Z. Zamanzadeh, L. Lourenço, J. Barros, European Journal of Environmental and Civil Engineering, 18, 81(2014)

[RJC-1636/2017] 